\title{
RELAÇÃO ENERGIA: PROTEÍNA NA NUTRIÇÃO DO TUCUNARÉ
}

\author{
Ana Maria Barreto de Menezes Sampaio ${ }^{1,4 *}$; Fernando Kubitza²; José Eurico Possebon Cyrino ${ }^{3}$ \\ ${ }^{1}$ Pós-Graduanda do Depto. de Produção Animal - USP/ESALQ. \\ ${ }^{2}$ Depto. de Pesquisa e Desenvolvimento - Projeto Pacu Ltda/Agropeixe Ltda, Rua 26 de agosto, 1957, salas 2 e 3 - \\ CEP: 79005-030 - Campo Grande, MS. \\ ${ }^{3}$ Depto. de Produção Animal - USP/ESALQ, C.P. 9 - CEP: 13418-900 - Piracicaba, SP. \\ ${ }^{4}$ Bolsista FAPESP. \\ *Autor correspondente <ambmsamp@carpa.ciagri.usp.br>
}

\begin{abstract}
RESUMO: O objetivo deste estudo foi avaliar o efeito da relação energia:proteína no desempenho e composição corporal do tucunaré. Para tanto, 196 alevinos de tucunarés (Cichla sp.), condicionados a aceitar alimentos secos, com peso médio vivo de $10 \mathrm{~g}$, foram estocados em gaiolas de tela de volume igual a $25 \mathrm{~L}$, alojadas em 16 caixas de cimento amianto com volume de $500 \mathrm{~L}$, instaladas em uma estufa e abastecidas por um sistema fechado de recirculação de água. Os peixes foram alimentados ad libitum com ração seca em duas refeições diárias, por um período de 65 dias com quatro rações isoenergéticas (3.500 kcal de ED kg-1 de ração), com níveis de proteína bruta de 41\%, 37\%, 33\% e 30\% de forma a obter uma relação ED:PB de 8, 9, 10 e 11 kcal de $E D \mathrm{~g}^{-1}$ de $\mathrm{PB}$, estabelecendo-se um delineamento experimental inteiramente casualizado com 4 tratamentos e 4 repetições. No início do experimento um lote de peixes foi sacrificado para determinação dos teores corporais de proteína, gordura, água e matéria mineral. No final do período experimental, foram sacrificados lotes de peixes de cada tratamento para nova análise de composição corporal. Os dados obtidos foram submetidos à análise de variância utilizando-se do software SAS, e aplicando-se regressão polinomial para avaliar o efeito das relações ED:PB nas variáveis analisadas ao nível de $5 \%$ de probabilidade. Os resultados permitem inferir que a exigência nutricional do tucunaré pode ser suprida por uma ração contendo entre 8 e 9

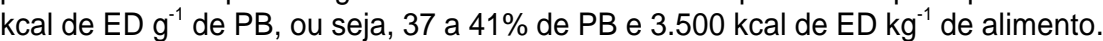

Palavras-chave: Cichla sp., taxa de eficiência, proteína, valor produtivo, energia bruta
\end{abstract}

\section{ENERGY: PROTEIN RATIO AND THE NUTRITION OF THE PEACOCK BASS}

\begin{abstract}
To evaluate the effect of the energy to protein ratio on the performance and body composition of the peacock bass (Cichla sp.), 196 fingerlings of the species weaned to accept dry feed, with an average body weight of $10 \mathrm{~g}$, were housed in $25 \mathrm{~L}$ cages, placed in 16, 500 L cement boxes, under a water reuse system, inside a greenhouse. Fish were fed ad libitum with a dry diet, twice a day, for 65 days with four iso-caloric rations $\left(3,500 \mathrm{kcal} \mathrm{DE} \mathrm{kg}^{-1}\right)$, with increasing levels of crude protein $30 \%, 33 \%, 37 \%$ and $41 \%$, establishing DE:CP ratios of $8,9,10$ and $11 \mathrm{kcal} \mathrm{DE} \mathrm{g}^{-1} \mathrm{CP}$, in a completely randomized design with 4 treatments and 4 replications. Before starting the experiment, a group of fish was slaughtered and the carcass content of protein, fat, water and ash were determined. At the end of the experimental period, groups of fish from each treatment were slaughtered for comparative carcass composition analysis. The results were analysed by ANOVA using the SAS statistical package for general linear model analysis, at $5 \%$ probability level. Results allow to infer that nutritional requirements of peacock bass can be met by diets containing between 8 an $9 \mathrm{kcal} \mathrm{DE} \mathrm{g}^{-1} \mathrm{CP}$, or 37

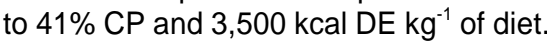

Key words: Chichla sp., efficiency ratio, protein, productive value, gross energy

\section{INTRODUÇÃO}

O tucunaré é uma espécie de peixe pertencente ao gênero Cichla sp. (Teleostei, Actinopterygii, Cichlidae), incluída entre as espécies nativas de grande importância para a pesca esportiva. Originário da bacia amazônica, o tucunaré é uma espécie de hábito alimentar carnívoro e tem demonstrado considerável eficiência no controle de peixes invasores em represas. Estas características, aliadas à excelência da qualidade da sua carne, tornam o tucunaré uma espécie potencialmente utilizável em piscicultura intensiva (Fontenele, 1948; Silva et al., 1980).

A criação intensiva da espécie, entretanto, é considerada muito difícil, uma vez que está sujeita aos entraves comuns à criação de espécies carnívoras: uso de estratégias inadequadas de preparo e monitoramento dos tanques de larvicultura, o acentuado canibalismo e a inabilidade em aceitar de imediato rações convencionais, e a baixa disponibilidade de rações comerciais de qualidade, nutricionalmente completas e bem balanceadas, que supram as exigências nutricionais destas espécies.

Segundo Lovell (1984), a relação energia:proteína exigida pelos peixes é menor que aquela exigida por animais de sangue quente, porque os peixes não têm que manter a temperatura corporal constante, despendendo menos energia para a atividade muscular e para manter a posição na água do que os animais terrestres, bem como gastam menos energia que os animais homeotérmicos para excretar os produtos nitrogenados. Isto possibilita aos peixes a utilização de proteína dietética como fonte de 
energia. Deste modo, rações balanceadas para a criação de peixes contêm 30 a $35 \%$ de proteína, ao passo que rações de frangos e suínos, por exemplo, contêm 18 a 23\%, ou 14 a 16\%, respectivamente (Lovell, 1984; Lovell, 1991).

A exigência protéica de uma espécie e o teor de proteína de uma ração são influenciados por fatores como tamanho do peixe, função fisiológica, qualidade da proteína e fatores econômicos. Porém, não há nenhuma evidência que a exigência em proteína, expressa em porcentagem da matéria seca, seja influenciada pela temperatura ambiente. Page \& Andrews (1973) demonstraram que, para o bagre do canal, $25 \%$ de proteína na ração foi adequada para peixes de 114 - $500 \mathrm{~g}$, mas um teor de 35\% de proteína induz crescimento mais rápido do que $25 \%$ de proteína para peixes com 14 a $100 \mathrm{~g}$.

A proteína é responsável pela maior parte do custo de uma ração (Robinson \& $\mathrm{Li}, 1997)$. Se o teor de energia de uma dieta não for suficiente, ou se a proteína for de baixa qualidade, ela será deaminada para servir como fonte de energia para o metabolismo. Uma baixa relação energia:proteína pode reduzir a taxa de crescimento devido ao aumento da demanda metabólica para excreção de nitrogênio. Excesso de energia na ração pode causar deposição excessiva de gordura nos peixes, reduzir consumo de alimento e inibir a utilização de outros nutrientes (Cho, 1990).

Geralmente, peixes ficam mais gordurosos quando alimentados com dietas contendo altas relações ED:PB. Lovell (1986) testou o ganho de peso x ganho de proteína de peixes que foram alimentados "ad libitum" com cinco níveis de energia digestível (ED): 2,2 a 4,6 kcal g ${ }^{-1}$ e duas porcentagens de proteína bruta (PB): 27 e $37 \%$ por dez semanas. $\mathrm{O}$ autor verificou que o ganho de peso aumentou conforme aumentou ED na dieta em ambos os níveis de proteína. Entretanto, o ganho de proteína aumentou conforme aumentaram os níveis de ED somente no nível mais alto de proteína. Isto mostra que os peixes alimentados com baixa proteína na dieta usam a energia adicional para acumulação de gordura ao invés de ganho de proteína.

Rojas \& Verdegem (1994), estudaram os efeitos de diferentes relações energia:proteína no crescimento do guapote (Cichlasoma managuense), uma espécie carnívora, de água doce, que vive bem em águas de temperatura variando de 25 a $30^{\circ} \mathrm{C}$, originária da América Central e conhecida pelos consumidores pela excelente textura e sabor de sua carne. Os resultados de Rojas \& Verdegem (1994) mostraram que a taxa de crescimento da espécie (fase de $4 \mathrm{~g}$ ) está em torno de 6 a $12 \mathrm{~g} \mathrm{~kg}^{-0,8}$ $\mathrm{dia}^{-1}$ e que 0 uso de dietas com uma relação energia: proteína maior que 8 a $9 \mathrm{kcal}^{\mathrm{k}}$ de $\mathrm{ED} \mathrm{g}^{-1}$ de $\mathrm{PB}$, com 3.300 kcal de ED e 35 a $40 \%$ de PB, não aumenta esta taxa de crescimento.

Verifica-se, então, que altos teores de gordura no alimento reduzem rendimento de carcaça, qualidade do pescado e tempo de armazenamento dos produtos processados. A utilização de um menor nível de proteína nas dietas seria recomendado, uma vez que seria mais econômico. Entretanto, se rendimento e qualidade do produto final forem considerados em conjunto, o uso de níveis mais elevados de proteína seria mais apropriado. Com base no exposto, foi desenvolvido o presente estudo com o tucunaré (Cichla sp.), com o objetivo de avaliar o efeito da relação energia:proteína no desempenho e composição corporal, visando subsidiar o preparo de rações comerciais para peixes carnívoros tropicais, que viabilizem sua utilização em criações em regime intensivo.

\section{MATERIAL E MÉTODOS}

O presente estudo foi desenvolvido junto ao Setor de Piscicultura do Departamento de Produção Animal da Escola Superior de Agricultura "Luiz de Queiroz", Universidade de São Paulo, Campus de Piracicaba-SP., durante o período de 6 de agosto a 11 de outubro de 1997.

Foram utilizados 196 alevinos de tucunarés (Cichla sp.), condicionados a aceitar ração granulada seca, com peso médio inicial de $10 \mathrm{~g}$. Os peixes foram estocados em 16 gaiolas de tela de polietileno de malha $5 \mathrm{~mm}$ e volume igual a $25 \mathrm{~L}$ ( $31 \mathrm{~cm}$ altura $\times 32 \mathrm{~cm}$ de diâmetro), alojados em 16 caixas de cimento amianto com volume de $500 \mathrm{~L}$, contendo 12 peixes cada. No período pré-experimental os peixes ficaram concentrados em 3 gaiolas de tela semeIhante àquelas usadas no período experimental, com volume igual a $120 \mathrm{~L}$. Neste período, os peixes recebiam ração comercial para espécies carnívoras, com $40 \%$ de PB e $3.500 \mathrm{kcal}^{\mathrm{de}} \mathrm{ED} \mathrm{\textrm {kg } ^ { - 1 }}$, à vontade, em duas refeições diárias.

As caixas estavam abrigadas em uma estufa, num sistema fechado de recirculação de água. A temperatura da água foi mantida em $27,7 \pm 1,5^{\circ} \mathrm{C}$, que era registrada diariamente durante os horários de alimentação. Os peixes foram mantidos em sistema de água parada, sendo que 0 nível de oxigênio dissolvido dentro das parcelas experimentais era mantido através de um soprador de ar de $550 \mathrm{~W}$. Os valores de oxigênio dissolvido (OD) na água das caixas eram registrados diariamente durante os horários de alimentação.

O aquecimento da água foi realizado através de aquecedores de $300 \mathrm{~W}$ ligados a tomadas independentes para cada caixa de água. A difusão de ar nas caixas foi feita através de secções de mangueiras microperfuradas com $75 \mathrm{~cm}$ de comprimento.

Foram estabelecidos 4 tratamentos que consistiam de quatro rações isoenergéticas $\left(3.500 \mathrm{kcal}^{-10} \mathrm{ED} \mathrm{kg}^{-1}\right.$ de ração), com 8, 9, 10 e $11 \mathrm{kcal}^{\mathrm{c}}$ de ED g ${ }^{-1}$ de PB (ED:PB) que foram formuladas de forma que $70 \%$ da proteína bruta fosse de origem animal - farinha de peixe e farinha de ovo e os $30 \%$ restantes de origem vegetal - farelo de soja e milho. As rações experimentais foram elaboradas com base em análises da composição química dos ingredientes (TABELA 1), realizadas pelo Laboratório de Nutrição Animal do Departamento de Zootecnia da ESALQ-USP. As análises dos ingredientes e a composição das rações estão apresentados nas TABELAS 1 e 2, respetivamente. 
Os peixes foram alimentados manualmente, à vontade, em duas refeições diárias (8:00 h e 17:00 h). A biomassa média, consumo de ração e conversão alimentar eram determinados em intervalos de 21 dias para cada gaiola. Com o objetivo de amenizar o

TABELA 1 - Análise bromatológica dos ingredientes. Valores expressos em $100 \%$ da matéria original.

\begin{tabular}{|c|c|c|c|c|}
\hline \multirow[b]{2}{*}{ Nutriente } & \multicolumn{4}{|c|}{ Ing redientes } \\
\hline & $\begin{array}{c}\text { Farinha } \\
\text { de peixe }\end{array}$ & $\begin{array}{c}\text { Farinha } \\
\text { de ovo }\end{array}$ & Mi lho & $\begin{array}{l}\text { Farelo } \\
\text { de soja }\end{array}$ \\
\hline Umidade (\%) & 6,82 & 3,09 & 12,99 & 11,87 \\
\hline Proteína ruta (\%) & 54,86 & 41,21 & 7,25 & 42,78 \\
\hline Fibra bruta (\%) & 0,45 & 0,30 & 2,32 & 5,69 \\
\hline $\begin{array}{l}\text { Extrato etéreo } \\
(\%)\end{array}$ & 6,15 & 41,67 & 5,11 & 2,06 \\
\hline $\begin{array}{l}\text { Matéria mineral } \\
(\%)\end{array}$ & 25,23 & 3,41 & 1,18 & 5,17 \\
\hline $\begin{array}{l}\text { Energia bruta } \\
\left(\mathrm{kcal} \mathrm{kg}^{-1}\right)\end{array}$ & $4.756,95$ & $6.914,46$ & $3.995,21$ & $4.187,64$ \\
\hline $\begin{array}{l}\text { Energia dige stível } \\
\left(\mathrm{kcal} \mathrm{kg}^{-1}\right)^{1}\end{array}$ & $4.174,95$ & $6.223,02$ & $1.624,85$ & $2.514,68$ \\
\hline $\begin{array}{l}\text { Extrativo não } \\
\text { nitrogenado (\%) }\end{array}$ & 6,49 & 10,32 & 71,15 & 32,42 \\
\hline
\end{tabular}

estresse dos peixes provocado pelo manejo, tanto para a montagem do experimento como para todas as biometrias, foi utilizado o anestésico benzocaína na dose 1:10.000.

No início do período experimental um lote de 4 peixes foi sacrificado, armazenado em ultra-congelador e posteriormente submetido à análise de composição corporal, onde foram determinados: proteína, extrato etéreo, umidade, fibra bruta e matéria mineral. Da mesma forma, no final do período experimental 4 peixes de cada tratamento foram sacrificados e congelados para posterior análise de composição corporal. Estas análises foram realizadas no Laboratório de Nutrição Animal do "Centro de Energia Nuclear na Agricultura" - CENA.

Ao final do período experimental, foram determinados os seguintes parâmetros para a avaliação dos diferentes tratamentos: conversão alimentar - CA (quantidade de alimento consumido/ganho de peso); sobrevivência; consumo de ração; ganho de peso - GP; valor produtivo da proteína - VPP\% [(proteína corporal final - proteína corporal inicial) x 100 / consumo de proteína]; taxa de eficiência protéica - TEP(ganho de peso/consumo de proteína); e retenção de energia bruta - REB\% [(energia corporal final - energia corporal inicial) $\times 100 /$ consumo de energia]. Em função da pequena quantidade de material biológico disponível, os dados de VPP\%, TEP e REB\% foram submetidos apenas a uma análise gráfica de tendência.

TABELA 2 - Composição das rações. Valores expressos em 100\% da matéria original.

\begin{tabular}{|c|c|c|c|c|}
\hline Ingre dientes (\%) & $\begin{array}{c}\text { Ração } 1(\mathrm{~T} 1) \\
8 \mathrm{kcal} \text { ED g }{ }^{-1} \mathrm{~PB}\end{array}$ & $\begin{array}{c}\text { Ração } 2 \text { (T2) } \\
9 \text { kcal ED g }{ }^{-1} \text { PB }\end{array}$ & $\begin{array}{c}\text { Ração } 3 \text { (T3) } \\
10 \text { kcal ED g }^{-1} \text { PB }\end{array}$ & $\begin{array}{c}\text { Ração } 4 \text { (T4) } \\
11 \text { kcal ED g }^{-1} \text { PB }\end{array}$ \\
\hline Farinha de peixe & 37,00 & 33,00 & 29,90 & 25,50 \\
\hline Farelo de soja & 27,60 & 21,00 & 18,00 & 14,00 \\
\hline Milho moído & 15,00 & 23,60 & 29,40 & 36,00 \\
\hline Farinha de ovo & 20,00 & 20,00 & 17,80 & 18,50 \\
\hline Óleo de soja & 0 & 2,00 & 4,50 & 5,60 \\
\hline Suplemento mineral ${ }^{1}$ & 0,1 & 0,1 & 0,1 & 0,1 \\
\hline Suplemento vitamínico ${ }^{1}$ & 0,3 & 0,3 & 0,3 & 0,3 \\
\hline Vitamina $\mathrm{C}$ & 0,05 & 0,05 & 0,05 & 0,05 \\
\hline Total & 100,05 & 100,05 & 100,05 & 100,05 \\
\hline Umidade, \% & 6,64 & 6,73 & 5,75 & 6,69 \\
\hline PB calculado $(\%)^{2}$ & 41,43 & 37,04 & 33,57 & 30,21 \\
\hline EB calculado $\left(\mathrm{kcal} \mathrm{kg}^{-1}\right)$ & $4.682,49$ & $4.762,72$ & $4.812,28$ & $4.872,19$ \\
\hline ED calculado (kcal kg-1) & $3.516,86$ & $3.515,65$ & $3.489,62$ & $3.471,68$ \\
\hline Extrato etéreo calculado (\%) & 11,95 & 12,00 & 11,13 & 11,40 \\
\hline Matéria mineral calculado (\%) & 11,62 & 10,37 & 9,43 & 8,22 \\
\hline ENN & 26,21 & 31,95 & 38,23 & 41,68 \\
\hline Fibra bruta calculado (\%) & 2,15 & 1,95 & 1,89 & 1,80 \\
\hline
\end{tabular}

${ }^{1}$ Suplementação/kg de alimento: Mn 40 mg; Fe 100 mg; Zn 100 mg; Cu 10 mg; Co 1 mg; I 1,5 mg; Se 0,45 mg; vit. A 36.000 UI; vit B 9 mg; vit $\mathrm{D}_{3} 4.500 \mathrm{Ul}$; vit. $\mathrm{E} 150 \mathrm{UI}$; vit. $\mathrm{B}_{12} 90 \mu \mathrm{g}$; vit. $\mathrm{B}_{1} 6 \mathrm{mg}$; vit. $\mathrm{B}_{2} 18 \mathrm{mg}$; vit $\mathrm{K}_{3} 4,5 \mathrm{mg}$; ácido fólico $9 \mathrm{mg}$; biotina $0,6 \mathrm{mg}$; ácido pantotênico $30 \mathrm{mg}$; ácido nicotínico $90 \mathrm{mg}$.

${ }^{2} 70 \%$ de fonte protéica de origem animal e $30 \%$ de fonte protéica de origem vegetal. 
O delineamento experimental utilizado foi inteiramente casualizado com 4 tratamentos e 4 repetições. Os dados foram submetidos à análise de variância utilizando-se do software SAS, e aplicando-se regressão polinomial para avaliar o efeito das relações ED:PB nas variáveis analisadas ao nível de $5 \%$ de probabilidade (Steel \& Torrie, 1980; Snedcor \& Cochran, 1989).

\section{RESULTADOS E DISCUSSÃO}

A qualidade da água permaneceu estável durante o período experimental. As médias dos parâmetros de qualidade da água monitorados nas unidades durante 0 experimento foram: $\mathrm{pH} 7,5$; temperatura $27,7 \pm 1,5^{\circ} \mathrm{C}$; oxigênio dissolvido $6,8 \pm 0,7 \mathrm{mg} \mathrm{L}^{-1}$; alcalinidade total $55 \mathrm{mg} \mathrm{L}^{-1}$ de equivalente $\mathrm{CaCO}_{3}$; dureza total $87 \mathrm{mg} \mathrm{L}^{-1}$ de equivalente $\mathrm{CaCO}_{3}$.

Os índices de desempenho e composição corporal dos alevinos de tucunaré utilizados no experimento, correspondentes à média das quatro unidades experimentais de cada tratamento, bem como os resultados do Teste de Tukey, estão apresentados na TABELA 3. O peso médio inicial dos alevinos mostrou-se uniforme, não apresentando diferença entre os tratamentos $(P \geq 0,05)$.
Em relação às médias de consumo de ração dos animais $(C R)$, apenas $T 1$ diferiu dos demais $(P \leq 0,05)$. Não foram observadas diferenças entre T2, T3 e T4 $(P \geq 0,05)$, onde os peixes apresentaram um decréscimo no consumo de ração conforme aumentou a relação ED:PB (Figura 1). Tal fato pode estar relacionado com a maior quantidade de óleo de soja na ração, em ordem crescente do tratamento 2 para o 4, o qual é uma fonte de energia prontamente disponível para os peixes, que neste caso, poderiam atingir a saciedade a partir da ingestão de uma menor quantidade de alimento. Trabalhos realizados por Page and

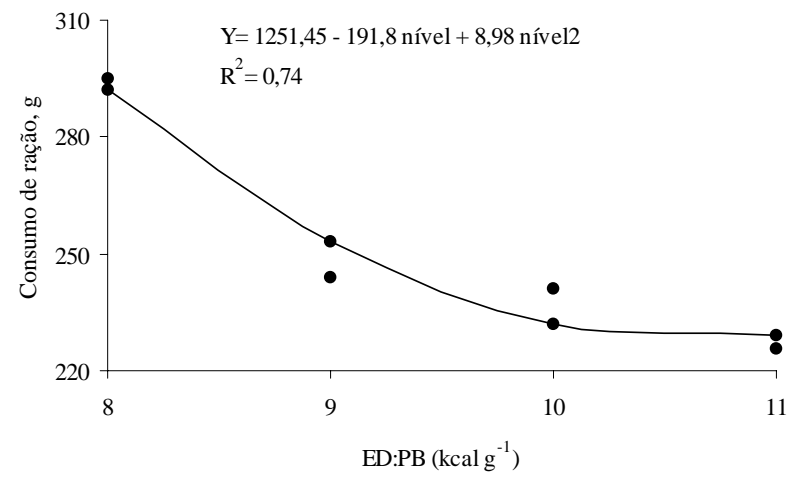

Figura 1 - Efeito da relação energia:proteína no consumo de ração de alevinos de tucunaré.

TABELA 3 - Médias dos índices de desempenho e composição corporal dos alevinos de tucunaré medidos durante o período experimental $\left(^{*}\right)$.

\begin{tabular}{|c|c|c|c|c|c|}
\hline & & & Tratamentos & & \\
\hline & T1 $8 \mathrm{kcal}$ & T2 $9 \mathrm{kcal}$ & T3 $10 \mathrm{kcal}$ & T4 $11 \mathrm{kcal}$ & C \\
\hline & $E D g^{-1} P B$ & $E D g^{-1} P B$ & $E D g^{-1} P B$ & $E D g^{-1} P B$ & $\operatorname{cv}(\%)$ \\
\hline Consumo ração, g & $295,28 \mathrm{a}$ & $243,93 \mathrm{~b}$ & 241,36 b & $225,96 \mathrm{~b}$ & 5,93 \\
\hline Ganho de peso da parcela, g & $245,17 \mathrm{a}$ & $199,26 \mathrm{~b}$ & $179,34 \mathrm{bc}$ & $149,09 \mathrm{c}$ & 10,81 \\
\hline C.A. & $1,20 b$ & $1,22 b$ & $1,35 \mathrm{ab}$ & $1,52 \mathrm{a}$ & 6,02 \\
\hline GDP/peixe, g & $0,315 a$ & $0,26 b$ & $0,23 \mathrm{bc}$ & $0,19 c$ & 10,31 \\
\hline Peso inicial/peixe, $g$ & $10,16 \mathrm{a}$ & $9,98 \mathrm{a}$ & $10,02 \mathrm{a}$ & $9,93 \mathrm{a}$ & 4,67 \\
\hline Peso final parcela, $g$ & $367,13 \mathrm{a}$ & $319,03 \mathrm{~b}$ & $299,53 \mathrm{bc}$ & $268,23 \mathrm{c}$ & 6,98 \\
\hline Peso final/peixe, $g$ & $30,59 a$ & $27,16 \mathrm{ab}$ & $24,96 \mathrm{bc}$ & $22,35 \mathrm{c}$ & 6,75 \\
\hline Composição Corporal ${ }^{4}$ & & & & & Inicial \\
\hline Água, \% & 72,13 & 71,28 & 71,23 & 70,93 & 76,63 \\
\hline Proteína, \% & 13,85 & 11,99 & 11,27 & 9,55 & 8,08 \\
\hline Extrato etéreo, \% & 5,32 & 7,05 & 9,24 & 8,60 & 5,07 \\
\hline Matéria Mineral, \% & 4,92 & 4,52 & 4,44 & 3,44 & 3,24 \\
\hline VPP, $\%^{1}$ & 33,14 & 31,33 & 29,08 & 23,21 & \\
\hline TEP ${ }^{2}$ & 2,00 & 2,21 & 2,21 & 2,18 & \\
\hline REB, $\%^{3}$ & 27,01 & 28,62 & 30,38 & 24,22 & \\
\hline
\end{tabular}

*Para cada variável, dietas com letras diferentes diferem a $(P \leq 0,05)$.

1Valor produtivo da proteína = (Proteína corporal final -proteína corporal inicial) x 100 / Proteína consumida.

${ }^{2}$ Taxa de eficiência protéica $=$ (Ganho de peso / Consumo de proteína).

${ }^{3}$ Retenção de energia bruta $=($ Ganho de energia corporal / consumo de energia) $\times 100$, considerando os valores de 5,7, kcal g-1 de proteína e $9,5 \mathrm{kcal} \mathrm{g}^{-1}$ de gordura.

${ }^{4}$ Os valores de composição corporal correspondem a somente uma amostra de cada tratamento. 
Andrews (1973), testando vários níveis de energia e proteína na dieta de bagre do canal, mostraram que o consumo de ração diminuiu conforme aumentaram os níveis de energia dietética, levando à conclusão que os peixes se alimentam para satisfazer suas necessidades em energia.

Para as variáveis ganho de peso (GP) e peso final da parcela (PFP), foram observadas diferenças entre o T1 e os demais tratamentos e entre T2 e T4 $(P \leq 0,05)$. Não foram observadas diferenças entre T2 e T3 e entre T3 e T4 $(P \geq 0,05)$. A aplicação do Teste de Tukey envolvendo os valores de peso final médio individual, mostrou uma diferença entre o T1 para T3 e T4 e entre o tratamentos $\mathrm{T} 2$ e T4 $(\mathrm{P} \leq 0,05)$. As médias de ganho de peso dos peixes de cada parcela variaram de 149,09 g (T4) a 245,17 g (T1).

No presente experimento, o ganho de peso dos alevinos de tucunaré de 10 a $30 \mathrm{~g}$ variou de 0,190 a 0,315 $\mathrm{g} / \mathrm{dia}$, estando um pouco abaixo do encontrado com outras espécies tropicais para esta fase (Figura 2 e 3 ). Valores comumente observados em produções comerciais para esta fase estão em torno de $0,4 \mathrm{~g}$ para o bagre do canal; $0,5 \mathrm{~g}$ para o tambaqui; 0,6 g para o Brycon sp; 0,6 g para tilápia do Nilo; 0,5 g para carpa comum; 0,5 g para o pacu e $0,7-0,9 \mathrm{~g} /$ dia para o pintado. Entretanto, o ideal seria comparar o ganho de peso dos peixes deste experimento com aquele obtido em outros experimentos realizados com a mesma espécie, mas não existem na literatura referências a trabalhos de avaliação de ganho de peso de tucunarés alimentados com ração.

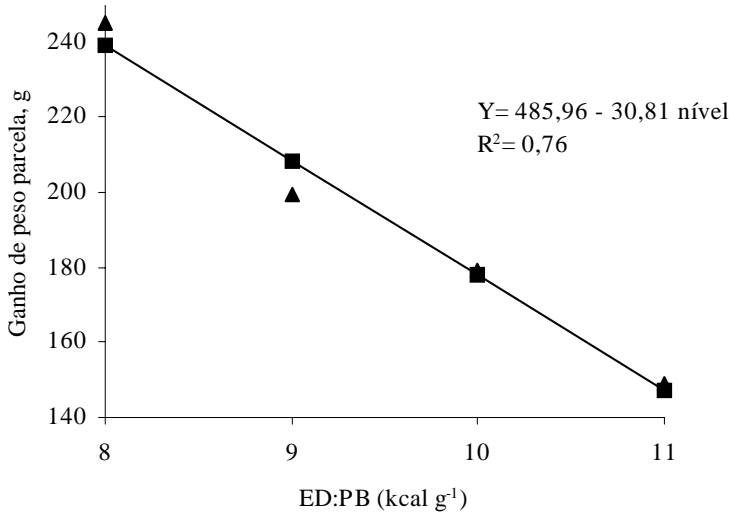

Figura 2 - Efeito da relação energia:proteína no ganho de peso de alevinos de tucunaré.

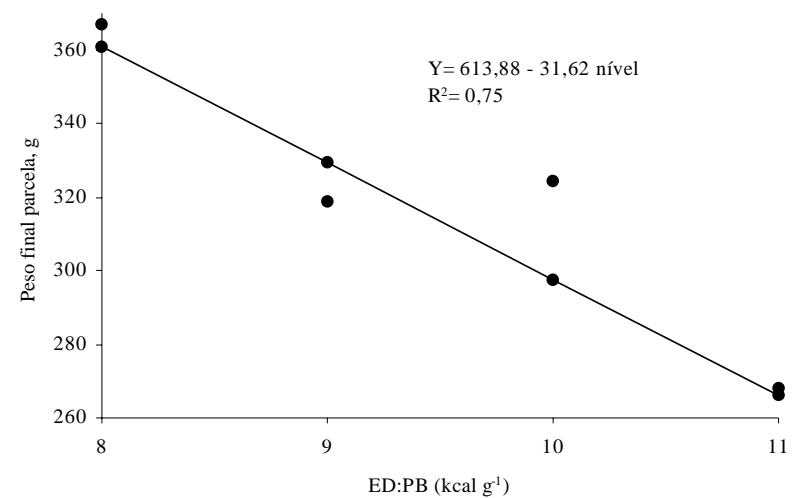

Figura 3 - Efeito da relação energia:proteína no peso final de alevinos de tucunaré.
Trabalhos realizados com outras espécies de peixes carnívoros mostraram resultados semelhantes. Lee \& Putnan (1973), testando rações com várias relações $\mathrm{ED}: \mathrm{PB}$, também demonstraram que as trutas comem para satisfazer suas necessidades em energia. Dietas com altos níveis de energia, contendo $24 \%$ óleo de peixe, proporcionaram ótimo crescimento, e neste nível de inclusão de lipídio na dieta, o nível de proteína pode ser reduzido em um terço, sem perda no ganho de peso e com uma melhora na utilização de energia. Estes resultados indicaram que, se a relação energia:proteína é mantida em níveis apropriados, pode-se produzir trutas com sucesso com dietas com altos níveis de energia. Os peixes parecem ser eficientes em converter a proteína ingerida em gordura. Isto é possível, em parte, graças à habilidade que estes animais têm de excretarem o excesso de nitrogênio na forma de amônia, em contraste aos mamíferos, que gastam energia na formação da uréia excretada na urina (Lovell, 1988; Cho, 1990). A associação positiva entre a quantidade de proteína digestível na dieta e o ganho de peso, sugere que a quantidade e a qualidade da proteína influenciam a taxa de crescimento do peixe. Entretanto, esta relação parece ter uma importância secundária quando associada à relação entre energia e a taxa de crescimento $(C h o, 1990)$. Embora a utilização dos coeficientes de digestibilidade da energia apresentados de Sullivan \& Reigh (1995) para o "striped bass híbrido", tenha servido adequadamente aos propósitos deste estudo, sugerimos que a realização de novos trabalhos com espécies carnívoras de clima tropical seja feita com coeficientes de digestibilidade dos nutrientes determinados especificamente para estas espécies, visto que a capacidade de utilização da energia difere entre espécies de clima temperado e tropical.

Foi observada uma piora na conversão alimentar em função do aumento da relação ED:PB. Não houveram diferenças entre T1, T2 e T3, assim como entre T3 e T4 $(P \geq 0,05)$. Tais valores podem ser considerados muito bons. Estes resultados podem ser atribuídos às boas condições de qualidade de água nas unidades experimentais e ao bom manejo durante as biometrias que assegurou uma redução no estresse dos animais e à boa qualidade das rações experimentais (Figura 4). Considerando que a proteína é o nutriente mais caro na composição de rações

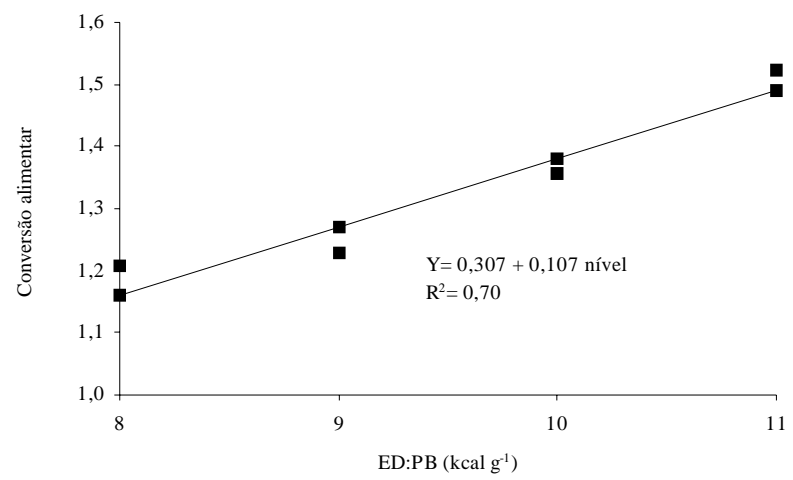

Figura 4 - Efeito da relação energia:proteína na conversão alimentar de alevinos de tucunaré. 
para peixes (Lovell, 1989), as rações comerciais contêm um nível mínimo necessário deste nutriente com um perfil de aminoácidos essenciais balanceado para garantir um adequado crescimento aos peixes. A diminuição nos valores de CA no decorrer do período experimental pode ser atribuída a vários fatores como, por exemplo, adaptação dos peixes ao ambiente e às rações, crescimento dos peixes e variações da temperatura da água, visto que os dados da primeira biometria foram obtidos com médias de temperatura de $26^{\circ} \mathrm{C}$, e as biometrias seguintes foram realizadas com médias de temperatura de $28^{\circ} \mathrm{C}$. Os peixes, que são animais pecilotérmicos, apresentam atividade metabólica diretamente relacionada com a temperatura da água. Para espécies de clima tropical, o aumento da temperatura da água promove melhoria nos índices de CA devido ao aumento da taxa de crescimento, enquanto as exigências para manutenção permanecem praticamente constantes e permitem que maior quantidade da energia ingerida como alimento seja utilizada para o crescimento (Lovell, 1989; Cho, 1990; Lovell, 1984).

Com relação à composição corporal dos animais utilizados no experimento, foi observado que os teores de proteína variaram de 9,55\% (T4) a 13,85\% (T1), enquanto que a composição corporal em lipídios oscilou de 5,32\% (T1) a 9,24\% (T3), reduzindo para 8,6\% (T4) (Figura 5).

Segundo Garling \& Wilson (1976) um aumento na concentração de lipídios em geral condiciona uma diminuição na porcentagem de água, proteína e cinzas, na carcaça. O mesmo fenômeno foi observado no presente estudo, onde a maior deposição (ganho) de proteína ocorreu em peixes alimentados com rações contendo baixa relação ED:PB, bem como a relação ED:PB foi positivamente correlacionada ao conteúdo de gordura corporal. Estes resultados corroboram relatos de Page \& Andrews (1973) e Robinson \& Li (1997), que observaram que o aumento da concentração de proteína corporal é dependente da relação ED:PB da ração.

O valor produtivo da proteína (VPP) variou de $23,21 \%$ (T4) a 33,14\% (T1), como pode ser observado na Figura 6. Existe uma relação característica entre o nível

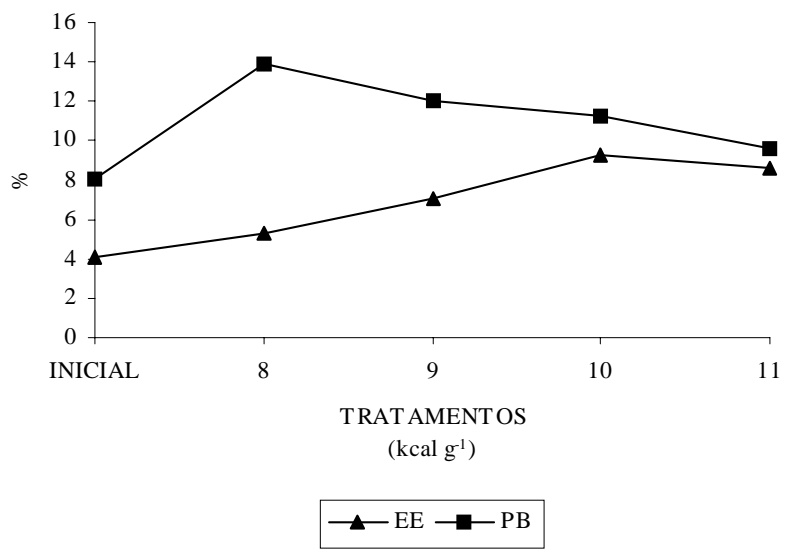

Figura 5 - Efeito da relação energia: proteína na composição de carcaça de alevinos de tucunaré. de proteína da dieta e a utilização da proteína pelo peixe. Esta relação pode ser descrita como segue: quando a dieta apresenta baixos níveis em energia, a utilização de proteína é baixa; conforme o nível de proteína aumenta, a utilização de proteína também aumenta e alcança um máximo perto do nível mínimo de proteína exigido; em níveis de proteína além do mínimo exigido, a utilização de proteína diminui. No presente trabalho, a dieta contendo menor concentração energética foi acompanhada de um maior consumo e a proteína consumida foi eficientemente transformada em proteína corporal, havendo um menor acúmulo de gordura na carcaça.

Estudos desenvolvidos por Murray et al. (1977), com bagre do canal, utilizando dietas com 25 e $35 \%$ de $\mathrm{PB}$, revelaram um aumento na conversão em proteína (proteína consumida/g ganho em proteína) em função do aumento da porcentagem de lipídio na dieta de 5 para $12 \%$. Este aumento no teor de lipídio na ração resultou em um efeito economizador da proteína consumida permitindo que mais proteína fosse depositada nos tecidos.

Os valores de retenção de energia bruta (REB) variaram de $27,01 \%$ (T1) a 30,38\% (T3), apresentando uma diminuição para $24,32 \%$ (T4), ou seja, apresentaram a mesma tendência de acumulação de lipídios na carcaça, como pode ser observado na Figura 6. Estes resultados estão de acordo com aqueles obtidos por Reinitz \& Hitzel (1980) com truta arco-íris.

A taxa de eficiência protéica (TEP) neste estudo variou de 2,0 (T1) a 2,21 (T2 e T3) e 2,18 (T4), seguindo a mesma tendência de variação dos outros parâmetros, como mostra a Figura 7. A TEP foi maior para T2 e T3, porém os valores foram muito próximos. Trabalhos realizados por Papaparaskeva \& Alexis (1986), demonstraram que um aumento nos teores de lipídios e carboidratos em rações para peixes, pode resultar em maiores valores de TEP. Um efeito economizador da proteína pelos lipídios tem sido demonstrado por vários autores, tanto com espécies carnívoras como onívoras (Rojas \& Verddegem, 1994; Li \& Lovell, 1992 a,b; Daniels \& Robinson, 1986). Todos os valores de composição corporal observados neste trabalho, assim como os valores

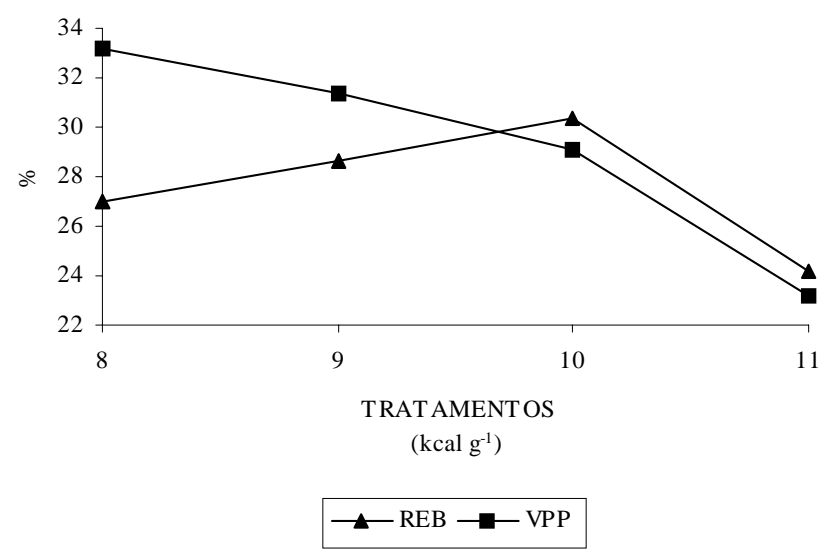

Figura 6 - Variação dos valores de REB\% e VPP\% em função da variação das relações energia: proteína nas dietas. 


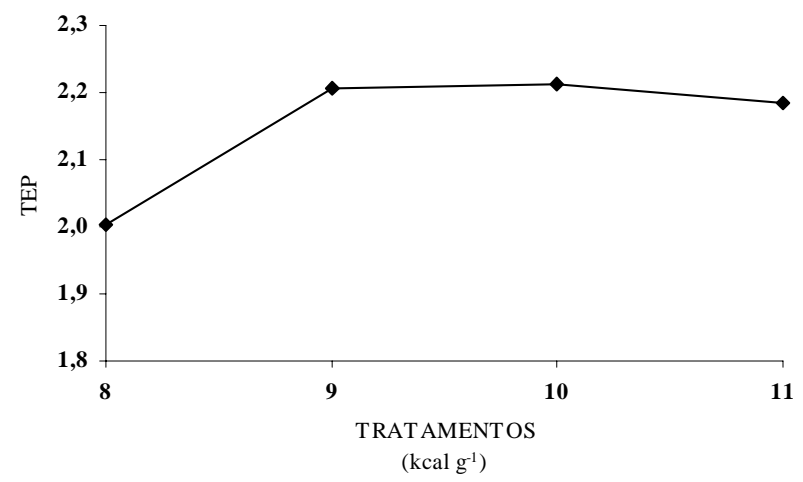

Figura 7 - Variação dos valores de TEP em função da variação das relações energia:proteína nas dietas.

de VPP\%, REB\% e TEP, são semelhantes àqueles encontrados por Kubitza (1990) para o pacu.

A discussão acima indica que uma relação ED:PB maior que 8 a $9 \mathrm{kcal} \mathrm{g}^{-1}$ não induz um maior ganho de peso do tucunaré mantido nas condições deste experimento. Deste modo, dietas com níveis subótimos de proteína (mínimo exigido), podem resultar em taxas de conversão em proteína mais eficientes, com maior economia no manejo alimentar da espécie.

\section{CONCLUSÕES}

- A melhor relação ED:PB para o tucunaré de 10 a $30 \mathrm{~g}$ foi de $8 \mathrm{kcal} \mathrm{g}^{-1}$, considerando uma ração com $41 \%$

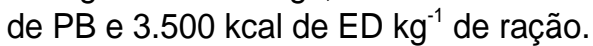

- Considerando que a exigência em proteína diminui com o aumento do tamanho do peixe, infere-se que peixes maiores podem consumir uma ração com $37 \%$ de PB e $9 \mathrm{kcal} \mathrm{g}^{-1}$ de relação ED:PB e apresentar satisfatório crescimento, conversão alimentar e boa qualidade de carcaça.

- Este trabalho foi realizado com base em tabelas de exigências nutricionais de outras espécies carnívoras de clima temperado e deve, deste modo, assumir importância significativa no embasamento de futuras pesquisas com espécies carnívoras tropicais.

\section{REFERÊNCIAS BIBLIOGRÁFICAS}

CHO, C.Y. Fish nutrition, feeds, and feeding: with special emphasis on salmonid aquaculture. Food Reviews International, v.6, p.333-357, 1990.

DANIELS, W.H.; ROBINSON, E.H. Protein and energy requirements of red drum. Aquaculture, v.53, p.232-243, 1986.

FONTENELE, O. Um caráter sexual secundário extragenital nos tucunarés (Actnopterygii, Cichlidae). Revista Brasileira de Biologia, v.8, p.185-188, 1948.

GARLING, D.M.; WILSON, R.P. Optimum dietary protein-toenergy ratios for channel catfish fingerlings, Ictalurus punctatus. Journal of Nutrition, v.106, p.1368-1375, 1976.
KUBITZA, F. Substituição total da farinha de peixe pelo farelo de soja em rações para alevinos de pacu (Piaractus mesopotamicus Holmberg, 1887), suplementadas com metionina. Piracicaba, 1990. 80 p. Dissertação (Mestrado) Escola Superior de Agricultura “Luiz de Queiroz”, Universidade de São Paulo.

LEE, D.J.; PUTNAM, G.B. The response of Rainbow Trout to varying protein/energy ratios in a test diet. Journal of Nutrition, v.103, p.916-922, 1973.

LI, M.; LOVELL, R.T. Comparison of satite feeding and restricted feeding of channel catfish with various concentrations of dietary protein in production ponds. Aquaculture, v.103, p.165-175, 1992a.

LI, M.; LOVELL, R.T. Comparison of feed conversion, dressing yield, and muscle composition for second-and third-year channel. The Progressive Fish-Culturist, v.54, p.171-173, 1992b.

LOVELL, R. T. Use of soybean products in diets for aquaculture species. American Soybean Association Technical Bulletin, v.AQ21-90 6/7, p.1-16, 1984.

LOVELL, R.T. Weight gain versus protein gain for evaluating fish feeds. Aquaculture Magazine, v.12, p.45-47, 1986.

LOVELL, R. T. Nutrition and feeding of fish. New York: Van Nostrand Reinhold, 1989. 260p.

LOVELL, R. T. Nutrition of Aquaculture Species. Journal of Animal Science, v.69, p.4193-4200, 1991.

MURRAY, M.W.; ANDREWS, W.; DELOACH, H.L. Effects of dietary lipids, dietary protein and environmental temperature on growth, feed conversion and body composition of channel catfish. Journal of Nutrition, v.107, p.272-280, 1977.

PAGE, J.W.; ANDREWS, J.W. Interactions of dietary levels of protein and energy on channel catfish (Ictalurus punctatus). Journal of Nutrition, v.103, p.1339-1346, 1973.

PAPAPARASKEVA, E.; ALEXIS, M. Protein requirements of young grey mullet, Mugil capito. Aquaculture, v.52, p.105-115, 1986.

REINITZ, G.; HITZEL, F.N. Formulation of practical diets for rainbow trout based on desired performance and body composition. Aquaculture, v.19, p.243-252, 1980.

ROBINSON, E.H.; LI, M.H. Low protein diets for channel catfish Icatalurus punctatus raised in earthen ponds at high density. Journal of the World Aquaculture Society, v.28, p.224-229, 1997.

ROJAS, J.B.U.; VERDEGEM, M.C.J. Effects of the protein:energy ratio in isocaloric diets on the growth of Cichlasoma managuense (Günther 1869). Aquaculture, v.25, p.631-637, 1994.

SILVA, J.W.B.; CHACON, J.O.; SANTOS, E.P. dos. Curva de rendimento do Tucunaré pinima Cichla temensis (Humboldt, 1833), do açude público "Estevam Marinho"(Curemas, Paraíba, Brasil) (Pisces, actinopterygl Cichlidae). Revista Brasileira de Biologia, v.40, p.203-206, 1980.

SNEDCOR, G.W.; COCHRAN, W.S. Statistical methods. 8.ed. Ames: The lowa State University Press, 1989. 503p.

STEEL, R.G.D.; TORRIE, J.H. Principles and procedures of statistics: a biometrical approach. New York: McGraw-Hill, 1980.

SULLIVAN, J.A.; REIGH, R.C. Apparent digestibility of selected feedstuffs in diets for hybrid striped bass (Morone saxatilis $\mathrm{x}$ Morone chrysops). Aquaculture, v.138, p.313-322, 1995.

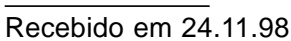

